\title{
P-50
}

\section{Mutagenicity Effect of Centella Asiatica In Aqueous Extract Via Ames Test}

\author{
Florinsiah binti Lorin $^{\mathrm{a}, \mathrm{b}}$, Farida Zuraina Yusof ${ }^{\mathrm{a}}$, Nor Fadilah Rajab ${ }^{\mathrm{b}}$
}

${ }^{a}$ Faculty of Applied Sciences, Universiti Teknologi MARA,40450, Shah Alam, Selangor; ${ }^{b}$ Toxicology Laboratory, Faculty of Health Sciences, Universiti Kebangsaan Malaysia, Jalan Raja Muda Abdul Aziz, 50300 Kuala Lumpur, Wilayah Persekutuan, Malaysia

Centella asiatica L. or locally known as Pegaga nyonya is a weakly aromatic smelling herb that belongs to a genus of the plant family Apiaceae (Umbelliferare). It has been used widely in folk medicine for hundreds of years to treat a wide range of illness. In this study, the mutagenic potential of $\mathrm{C}$. asiatica leaves and roots in aqueous extracts were determined using the Ames test. The method involved was pre-incubation on Salmonella typhimurium TA 98 and TA 100 bacterial strains in the presence and absence of metabolic activator S9 system. The extracts were evaluated using two-fold value of the number of revertant's colony in negative control plate as cut-off point, to determine the mutagenicity effects. The results showed that all aqueous extracts of the leaves and roots of C.asiatica were non mutagenic towards TA98 and TA100 strain with and without S9 metabolic activation for all concentration studied. In conclusion, C. asiatica leaves and roots aqueous extract were non mutagenic on both S.typhimurium strains and safe to be used as part of the traditional medicine.

Keywords: Ames assay, Centella asiatica, Mutagenicity effect, Salmonellatyphimurium, TA98, TA100. 